Article

\title{
Aerobic Methanol Oxidation over Unsupported Nanoporous Gold: The Influence of an Added Base
}

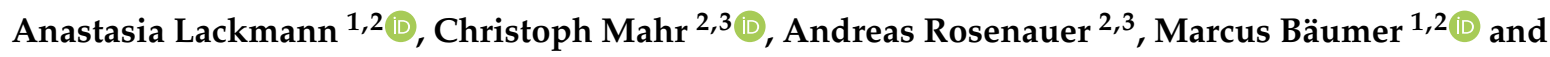 \\ Arne Wittstock 1,2,*iD \\ 1 Institute of Applied and Physical Chemistry and Center for Environmental Research and Sustainable \\ Technology, University Bremen, Leobener Str. UFT, 28359 Bremen, Germany; \\ lackmann@uni-bremen.de (A.L.); mbaeumer@uni-bremen.de (M.B.) \\ 2 MAPEX Center for Materials and Processes, University Bremen, Bibliothekstr. 1, 28359 Bremen, Germany; \\ mahr@ifp.uni-bremen.de (C.M.); rosenauer@ifp.uni-bremen.de (A.R.) \\ 3 Institute of Solid State Physics, Otto-Hahn-Allee NW1, Universität Bremen, 28359 Bremen, Germany \\ * Correspondence: awittstock@uni-bremen.de; Tel.: +49-421-2186-3400
}

Received: 25 March 2019; Accepted: 30 April 2019; Published: 6 May 2019

check for updates

\begin{abstract}
We studied the aerobic oxidation of methanol over nanoporous gold catalysts under neutral and alkaline conditions. We find that under neutral conditions the catalyst has an activation period of about $10 \mathrm{~h}$ while upon addition of a base the catalyst becomes active right away. After this activation period, however, the activity of the catalyst is in both cases similar. Moreover, the selectivity was not affected by the base. We tested different bases and found the largest effect when adding $\mathrm{OH}^{-}$. The cation, however, does not play a role. We conclude that it is $\mathrm{OH}^{-}$, which is impacting the reaction and propose a mechanism for the suppression of the activation period. While the catalytic cycle, i.e., the reaction of methanol on the catalyst surface seems unaffected, the transient adsorption of $\mathrm{OH}^{-}$ onto the surface can facilitate the activation of molecular oxygen by donating electrons to the surface. Due to the intermediate formation of oxidic Ag species, an effective segregation of surface-near Ag can be induced, which increases the abundance of $\mathrm{Ag}$ being essential for the activation of oxygen at the surface. In this way, a more efficient pathway for the generation of active oxygen is opened, allowing the reaction to set in faster.
\end{abstract}

Keywords: aerobic oxidation of methanol; nanoporous gold catalyst; addition of base; catalyst activation

\section{Introduction}

Nanoporous gold (npAu) has recently emerged as a promising solid catalyst for selective oxidation reactions [1,2]. In particular, one of the first catalytic reactions studied on npAu was the oxidation of primary alcohols. This new catalyst showed a remarkable activity and selectivity towards valuable partial oxidation products already at moderate temperatures (i.e., below $100{ }^{\circ} \mathrm{C}$ ), thus suggesting interesting perspectives for its use in "green" organic transformations as an alternative to processes, which are nowadays carried out only under much harsher reaction conditions [3,4]. In particular, aerobic oxidation, using molecular oxygen $\left(\mathrm{O}_{2}\right)$ from ambient air as oxidant, is an important step towards a more sustainable and "greener" chemistry. Accordingly, the growing interest in and research on npAu as a catalyst for highly selective oxidative self and cross-coupling of alcohols fits to this demand [5-7].

Nanoporous gold is usually prepared by dealloying, i.e., by a selective dissolution of a less-noble metal from a binary or multicomponent AuM alloy (e.g., $\mathrm{M}=\mathrm{Ag}, \mathrm{Cu}, \mathrm{Al}$ ) [8]. AuAg alloys have been most intensively used for this purpose as $\mathrm{Au}$ and $\mathrm{Ag}$ form a solid solution (i.e., they form no 
intermetallic compound) and-as the atomic radii are also very similar-stress generation during the dealloying process is avoided. During removing the less-noble metal chemically or electrochmically, an interconnected three-dimensional network is formed with ligament and pore sizes typically in the range of $20-50 \mathrm{~nm}$. Whereas Au nanoparticles in the range of a few $\mathrm{nm}$ supported on suitable supports are known to be catalytically active for a long time, catalytic activity of this unsupported material was initially unexpected. Extensive research after first reports in 2006 and $2007[9,10]$ revealed that its catalytic activity can be attributed to two primary factors [11]. One is the surface roughness, i.e., the density of low-coordinated atoms $[12,13]$ on the surface of the npAu ligaments, which, according to TEM studies, is similar to $5 \mathrm{~nm}$ Au nanoparticles so that the surfaces of the npAu ligaments expose a comparable density of edge and kink sites. Such low-coordinated sites are known to increase the adsorption strength of reactants and at the same time lower the activation barriers for breakage of, e.g., C-H bonds [14].

The second factor, explaining the ability of npAu to activate molecular oxygen even in the absence of an oxide support, has been attributed to residual Ag [15-17], which remains in the material in the range of a few atom $\%$ after the dealloying process. It has been suggested [9] and supported by theoretical DFT studies [18-22] that Ag clusters or bimetallic AuAg sites are able to activate molecular oxygen $\left(\mathrm{O}_{2}\right)$ - a crucial step that is not possible on pure Au. The reactive $\mathrm{O}$ atoms formed from $\mathrm{O}_{2}$ dissociation in this way can subsequently spill over to surrounding Au sites and oxidize adsorbed reactants and intermediates. Theoretical studies have shown that the presence of $\mathrm{Ag}$ in npAu increases the adsorption energy of $\mathrm{O}_{2}$ and lowers its dissociation barrier significantly $[18,19]$. Consistent with that, the activity of CO oxidation increases as the residual Ag content is increased for npAu samples [23]. In the case of the partial oxidation of methanol on npAu to methyl formate (MeFm) in the gas-phase, the observed effect of residual Ag was two-fold: On the one hand, the overall activity increased on samples with a higher Ag content; on the other hand, the selectivity to the partial oxidation product methyl formate (MeFm) dropped in favour of deep oxidation to $\mathrm{CO}_{2}$ and $\mathrm{H}_{2} \mathrm{O}$. This loss of selectivity was attributed to a higher abundance of reactive oxygen on the surface with more $\mathrm{Ag}$ and to a stronger binding of all reactants, intermediates, and products on Ag-sites [6].

In the liquid phase, the addition of a base was found to significantly increase the catalytic activity in case of alcohol oxidation over supported Au nanoparticles [3,24-27]. Especially, the addition of alkali hydroxides showed the largest promoting effect [28]. However, it was demonstrated that also weaker bases, like carbonates, could increase the catalytic activity [29]. Yet, systematic investigations of the influence of various bases on the catalytic performance or regarding the influence of the base on the mechanism are missing so far. In case of $n p A u$, the role of base promoters for the alcohol oxidation in the liquid phase was investigated in just one pioneering work performed by Ding et al. who investigated the oxidation of D-glucose in water with $\mathrm{O}_{2}$ under basic conditions. These authors observed a significant increase of the activity as compared to neutral conditions, using $\mathrm{NaOH}$ as a base [30]. To contribute to a deeper understanding of this effect, we conducted a series of experiments with several alkali hydroxides (as well as weak bases) and studied their influence on the oxidation of methanol under various experimental conditions.

In case of supported gold nanoparticles, the increase of the catalytic activity by addition of a base has been interpreted by some authors as being related to the generation of hydroxyl ions under basic conditions, which could (1) transiently adsorb on the surface and participate in the surface reactions by providing electrons $\left(\mathrm{OH}^{-} \rightarrow \mathrm{OH}^{*}+\mathrm{e}^{-}\right)$for the reduction and activation of oxygen [31]. Alternatively, they can deprotonate methanol already in the solution (2) and thus-in addition to the electron donating effect-facilitate the formation of surface methoxy species $\left(\mathrm{CH}_{3} \mathrm{OH}+\mathrm{OH}^{-} \rightarrow \mathrm{CH}_{3} \mathrm{O}^{-}+\mathrm{H}_{2} \mathrm{O} \rightarrow \mathrm{CH}_{3} \mathrm{O}^{*}+\right.$ $\left.\mathrm{e}^{-}+\mathrm{H}_{2} \mathrm{O}\right)$ [32]. Furthermore, two adsorbed $\mathrm{OH}$ species can undergo disproportionation (3) $\left(2 \mathrm{OH}^{*} \rightarrow\right.$ $\left.\mathrm{O}^{*}+\mathrm{H}_{2} \mathrm{O}^{*}\right)$, transiently creating a source of adsorbed $\mathrm{O}$ on the surface, as suggested by experiments on clean Au surfaces under UHV-conditions [33,34]. A last possibility (4) in which a base, such as $\mathrm{OH}^{-}$, could act upon the mechanism is by involvement in the oxidation reaction itself of course, for instance by facilitating the rate determining step which, in case of methanol oxidation, is the $\mathrm{H}$-elimination step: 
$\mathrm{CH}_{3} \mathrm{O}^{*}+\mathrm{OH}^{*} \rightarrow \mathrm{HCOH}^{*}+\mathrm{H}_{2} \mathrm{O}^{*}$. While calculations by Kaxiras et al. [35] suggest a higher activation energy for the abstraction of $\mathrm{H}_{\text {by }} \mathrm{OH}^{*}$ as compared to $\mathrm{O}^{*}$, an acceleration of this rate determining step cannot be excluded, in particular in the liquid phase where due to the presence of the solvent the situation is more complex. In any event, it is difficult in the case of supported nanoparticles to differentiate between effects resulting from the interaction of the base with the gold or with the support so that a study with unsupported Au being available in the form of npAu is desirable.

In the present work, we observed a drastic increase in the conversion after $24 \mathrm{~h}$ when adding an $\mathrm{OH}^{-}$-containing base as compared to the reaction carried out under neutral conditions. This higher conversion, however, was not due to a higher activity under basic conditions, but primarily due to the suppression of an activation period of the catalyst occurring under neutral conditions. To better understand this effect, we performed catalytic experiments using various bases and samples with different residual $\mathrm{Ag}$ content also partly fabricated by different dealloying techniques. Our study suggests that the main effect of a base $\left(\mathrm{OH}^{-}\right)$is the facilitated formation of an $\mathrm{O}^{2-}$ species from $\mathrm{O}_{2}$ activation by a transient supply of electrons.

\section{Results}

\section{1. $n p A u$ Characterization}

A number of representative npAu samples prepared from different AuAg alloys and using different preparation routes, i.e., free corrosion (FC) and galvanodynamically controlled dealloying (GCD), was structurally (SEM) and chemically (AAS) characterized. The data is given in Table 1 and in the Electronic supplementary Information 1 (ESI-1). By FC, npAu samples exhibiting the typical network of interconnected ligaments were obtained. The ligament diameters were found to be in a range of $30-50 \mathrm{~nm}$ and the residual $\mathrm{Ag}$ contents $x_{\mathrm{Ag}}$ were below 1 at $\% \mathrm{Ag}$. With GCD similar results were obtained: the ligament sizes, however, ranged here between $20 \mathrm{~nm}$ and $35 \mathrm{~nm}$. In contrast to FC, with GCD the residual Ag concentration can be varied, while keeping the ligament sizes constant so that structurally similar npAu samples with different Ag content can be obtained [36]. In the present case, the residual Ag content was varied between $\sim 1$ and $\sim 5$ at $\%$. The homogeneity of the ligament sizes throughout the monoliths was confirmed by SEM (Figures S1 and S2). The specific surface areas were determined by cyclic voltammetry and a value of $14 \pm 2 \mathrm{~m}^{2} / \mathrm{g}$ was found independent of the preparation method and the AuAg starting alloy. All samples were comparable to npAu samples previously studied in our group [36].

Table 1. Characteristics of npAu samples obtained by FC and GCD and prepared using different starting alloys. $L_{\mathrm{B}}$-the range of ligament sizes obtained from SEM, $L_{\mathrm{B}, \mathrm{Av}}$-determined average ligament size in the centre of a disk, and $x_{\mathrm{Ag}, \mathrm{AAS}}$ - remaining residual Ag content determined by AAS after dissolution of the npAu samples.

\begin{tabular}{cccc}
\hline Starting Alloy & $\boldsymbol{L}_{\mathbf{B}} / \mathbf{n m}$ & $\boldsymbol{L}_{\mathbf{B}, \mathbf{A v} / \mathbf{n m}}$ & $\boldsymbol{x}_{\mathbf{A g}, \mathbf{A A S} / \mathbf{a t} \%}$ \\
\hline $\mathrm{FC}$ & & & \\
$\mathrm{Au}_{30} \mathrm{Ag}_{70}$ & $30-50$ & $38.6 \pm 8.3$ & $0.9 \pm 0.1$ \\
$\mathrm{Au}_{25} \mathrm{Ag}_{75}$ & $30-50$ & $38.1 \pm 7.8$ & $0.7 \pm 0.2$ \\
\hline $\mathrm{GCD}$ & & & \\
$\mathrm{Au}_{30} \mathrm{Ag}_{70}$ & $20-35$ & $27.2 \pm 5.2$ & $0.8 \pm 0.2$ \\
$\mathrm{Au}_{25} \mathrm{Ag}_{75}$ & $20-35$ & $25.6 \pm 4.0$ & $0.8 \pm 0.1$ \\
$\mathrm{Au}_{25} \mathrm{Ag}_{75}$ & $20-35$ & $27.4 \pm 4.0$ & $1.5 \pm 0.2$ \\
$\mathrm{Au}_{25} \mathrm{Ag}_{75}$ & $20-35$ & $24.4 \pm 4.4$ & $3.9 \pm 0.6$ \\
\hline
\end{tabular}

Statistical analysis of SEM images acquired for npAu samples after catalysis (see Section 2.2.) revealed no significant change of the ligament sizes due to the catalytic reaction (Figure S3).

Furthermore, a detailed TEM study was conducted for one sample to investigate in depth possible changes of the surface morphology after catalysis (Figure S4). To this end, an npAu sample was 
prepared by $\mathrm{FC}$ using $\mathrm{Au}_{25} \mathrm{Ag}_{75}$ as starting alloy and employed for methanol oxidation under basic conditions (12 $\mathrm{mM}$ in methanol). The results of this study are compiled in Figure 1. Interestingly and in line with a previous study [13], the surface roughness of npAu is not changed during catalysis staying within error bars nearly constant $[5,13]$. Based on HRTEM measurements and the evaluation method described in Section 2 and in Ref. [5], the surface roughness was determined to be $\sim 22 \pm 2 \%$ after catalysis under basic conditions (Figure S5), which is comparable to the roughness of $\sim 25 \pm 3 \%$ reported previously for as-prepared samples and samples used as a catalyst under different catalytic conditions [36]. A detailed description of the procedure applied to extract these numbers from the HRTEM images is presented in Ref. [5].

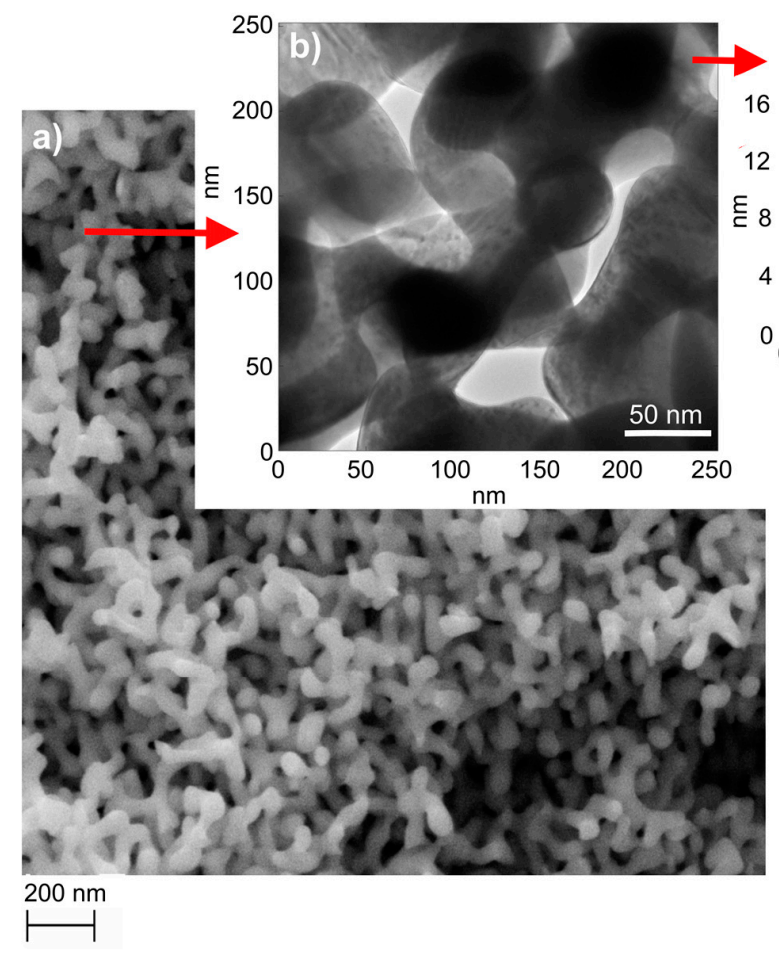

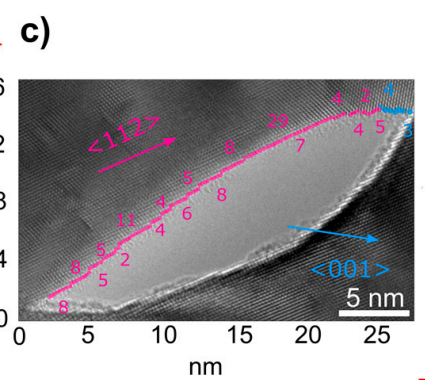
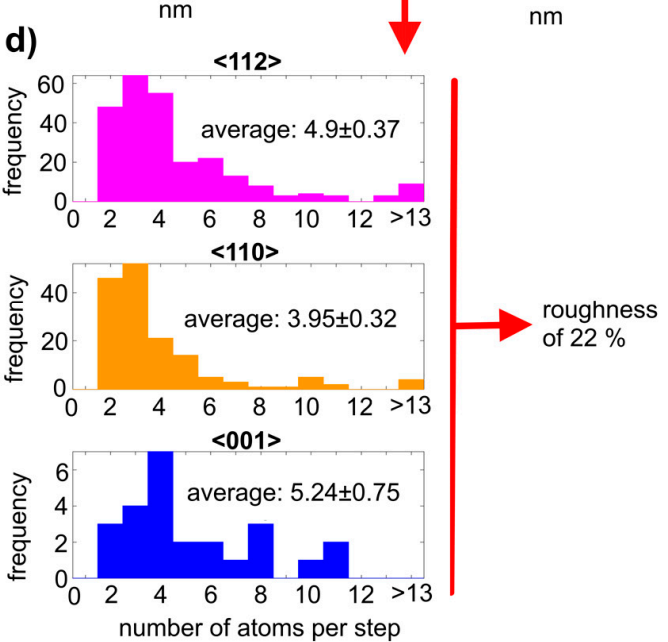

Figure 1. (a) Representative SEM and (b) TEM images of npAu after catalysis containing less than 1 at $\% \mathrm{Ag}$ and prepared via $\mathrm{FC}$ from a $\mathrm{Au}_{25} \mathrm{Ag}_{75}$ starting alloy. Catalytic methanol oxidation was performed at $60{ }^{\circ} \mathrm{C}$ and 3 bar oxygen for 24 hours with $12 \mathrm{mM} \mathrm{KOH}$ as a base. (c) The density of the low coordinated surface atoms was determined by measuring separations between surface steps in two-dimensional projections along $<112>,<110>$, and $<001>$ directions, counting the number of atoms per step in the TEM images, and (d) by weighting the average values with the reciprocal surface energies finally leading to the roughness of the catalysts surface.

\subsection{Aerobic Catalytic Investigations}

In a first set of experiments the impact of an $\mathrm{OH}$-containing base on the progression of the aerobic oxidation of methanol was studied. Not surprisingly, in the absence of oxygen or the catalyst no reaction took place, regardless of the experimental conditions, e.g., the addition of a base. In the presence of oxygen and the catalyst, though, the formation of methyl formate was observed. Two different scenarios where studied: Neutral conditions and the presence of a base $\mathrm{MOH}(12 \mathrm{mM}, \mathrm{M}=\mathrm{K}$, $\mathrm{Na}, \mathrm{Li}$ ) (Figure 2a). While under neutral conditions the production of methyl formate after $24 \mathrm{~h}\left(60^{\circ} \mathrm{C}\right.$, 3 bar $\mathrm{O}_{2}$ ) amounted to $0.5 \mathrm{~mol} / \mathrm{g}_{\mathrm{npAu}}$, this number increased by over $100 \%$ to about $1.25 \mathrm{~mol} / \mathrm{g}_{\mathrm{npAu}}$ upon addition of a base under otherwise same conditions. Notably, regardless whether $\mathrm{KOH}, \mathrm{NaOH}$, or $\mathrm{LiOH}$ was added to the reaction mixture (Figure S5a), the same promoting effect for the catalytic performance was obtained. The selectivity did not change. The product exclusively observed in the 
liquid phase was methyl formate in both cases. We also varied the concentration of the added bases (5-200 mM base in methanol), and found no differences indicating that only small catalytic amounts of $\mathrm{OH}^{-}$are necessary to influence the reaction and larger amounts neither had a beneficial nor detrimental effect. (Figure S5c-d).

a)

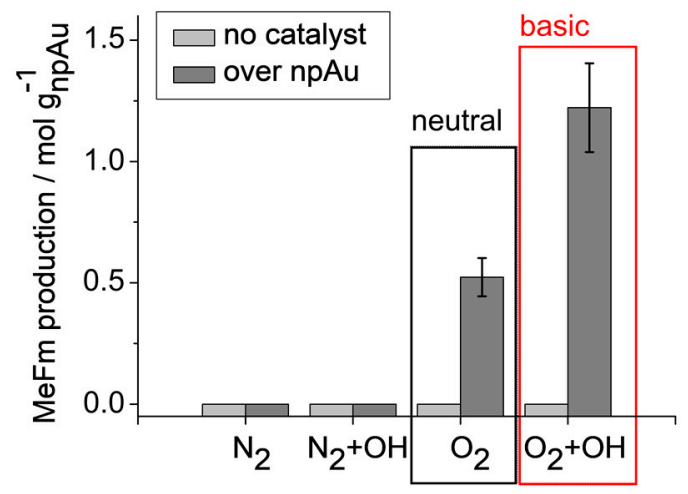

b)

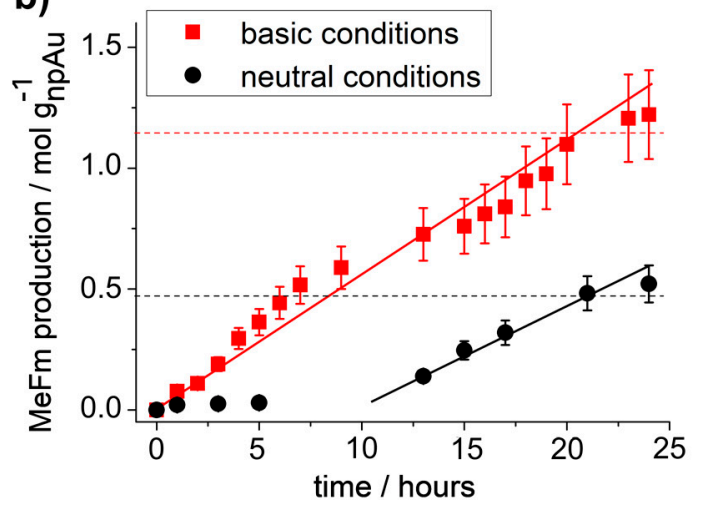

Figure 2. (a) Methyl formate (MeFm) production observed after $24 \mathrm{~h}$ at $60^{\circ} \mathrm{C}$ under different conditions: 3 bar $\mathrm{N}_{2}, 3$ bar $\mathrm{N}_{2}$, and $12 \mathrm{mM} \mathrm{MOH}$ added, 3 bar $\mathrm{O}_{2}$ and 3 bar $\mathrm{O}_{2}$ with $12 \mathrm{mM} \mathrm{MOH}$ added. All these four experiments were performed in presence as well as in the absence of npAu (1 at $\%$ residual $\mathrm{Ag}$ ) as catalyst. (b) Methanol oxidation at $60^{\circ} \mathrm{C}$ and $3 \mathrm{bar} \mathrm{O}_{2}$ as a function of reaction time: Comparison of the temporal evolution of MeFm formation under neutral as well as basic (12 $\mathrm{mM} \mathrm{MOH}$ methanol) conditions.

When measuring the production of methyl formate over time, the reason for the different conversions after $24 \mathrm{~h}$ becomes obvious (Figure $2 \mathrm{~b}$ and Figure S6). Under neutral conditions the catalyst is apparently inactive for the first $10 \mathrm{~h}$ and only subsequently the formation of methyl formate sets in. Such a behavior, i.e., the occurrence of an activation period, was already observed in previous studies in liquid [5] as well as in the gas phase [6]. The origin for this delayed activity is most likely twofold. On the one hand, the catalyst surface might be covered by some contaminants (e.g., hydrocarbons), which block active sites and need to be removed [37]. On the other hand, active sites for the activation of $\mathrm{O}_{2}$ might not be directly available on the fresh surface to a sufficient extent. Specifically, Ag atoms, which are believed to play an important role for the generation of active oxygen [18], might be buried underneath the surface of the ligaments [13] and need to segregate to the surface first.

In gas phase catalysis, this activation period was drastically reduced by a pretreatment of $\mathrm{npAu}$ samples with ozone at temperatures over $150{ }^{\circ} \mathrm{C}$ [37]. In our case, however, i.e., when using such a pretreated npAu catalyst in liquid phase, no beneficial effect on the activation period was observable [5]. Yet, upon addition of a base to the methanol, formation of methyl formate sets in right away, i.e., the catalyst showed no activation period (Figure 2b). From the beginning, an almost linear increase of the 
product methyl formate is observed over time, which is in agreement with a pseudo zero order kinetics, as expected for the large excess of methanol applied. Under neutral conditions, i.e., without the added base, the activity of the catalyst as judged by the slope of the linear increase after the activation period is very similar, implying that in both cases the reaction mechanism is not considerably affected by the presence of the base but just the activation characteristics. Noteworthy, after $24 \mathrm{~h}$ the catalyst activity slowed down and even leveled off (Figure S6). The origin of this deactivation of the catalyst under both conditions remains speculative but might be correlated to an accumulation of reaction intermediates on the catalyst surface. Furthermore, studies have shown that Ag can leach under liquid conditions $[38,39]$. This effect could also contribute to the deactivation of the catalyst over time.

Catalytic investigations using npAu samples fabricated using different starting alloys $\left(\mathrm{Au}_{25} \mathrm{Ag}_{75}\right.$ and $\left.\mathrm{Au}_{30} \mathrm{Ag}_{70}\right)$ and different preparation routes (FC and GCD) but with similar residual silver contents below 1 at $\%$ showed that the catalytic performance is independent of the AuAg starting alloy composition (Figure 3). The amount of methyl formate formed after $24 \mathrm{~h}$ was increased in all cases from $0.5 \mathrm{~mol} / \mathrm{g}_{\mathrm{npAu}}$ to $1.25 \mathrm{~mol} / \mathrm{g}_{\mathrm{npAu}}$ upon addition of the base $\left(60^{\circ} \mathrm{C}\right.$ and $\left.3 \mathrm{bar} \mathrm{O}_{2}\right)$ as a result of the suppression of the activation period in the latter case. This finding, however, is not too surprising, as the residual Ag content and the specific surface areas are similar. The fact that the differences in ligament and pore sizes for samples prepared by FC and GCD did not lead to significant differences in catalytic activity reveals that mass transport limitation by diffusion, which would depend on the pore sizes, did not play a role under the chosen experimental conditions.

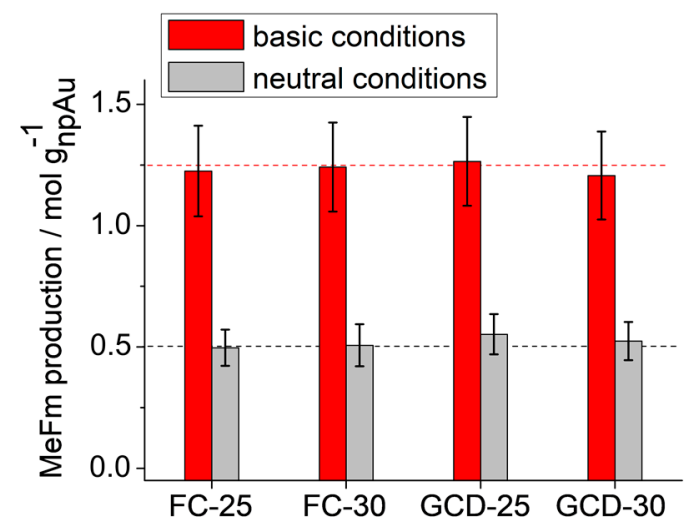

Figure 3. Production after $24 \mathrm{~h}$ over npAu samples containing less than 1 at $\%$ Ag prepared by FC using $\mathrm{Au}_{25} \mathrm{Ag}_{75}$ (FC-25) and $\mathrm{Au}_{30} \mathrm{Ag}_{70}$ (FC-30) as starting alloys as well as by GCD using $\mathrm{Au}_{25} \mathrm{Ag}_{75}$ (GCD-25) and from $\mathrm{Au}_{30} \mathrm{Ag}_{70}$ (GCD-30). The bar graphs show the comparison of the yield obtained under neutral and basic conditions. Catalytic experiments were performed at $60{ }^{\circ} \mathrm{C}$ and 3 bar $\mathrm{O}_{2}$ for $24 \mathrm{~h}$.

The impact of larger amounts of residual Ag was also studied using npAu samples prepared by GCD and containing residual Ag contents $x_{\mathrm{Ag}}$ up to 5 at $\%$ (total fraction in the sample) (Figure S7). In agreement with the samples containing low residual Ag contents, the production of methyl formate after $24 \mathrm{~h}$ was also considerably increased by addition of $\mathrm{MOH}$, as compared to neutral conditions. However, the overall conversion after $24 \mathrm{~h}$ decreased with increasing fractions of Ag. This behavior, i.e., a lower conversion by increasing amounts of residual $\mathrm{Ag}$, is in line with a previous study under neutral conditions $[13,36]$. The reason for the decreased activity can be twofold: on the one hand, it is likely that such a silver-rich npAu catalyst exhibits a lower selectivity towards the partial oxidation product and deep oxidation to $\mathrm{CO}_{2}$ takes place. On the other hand, larger patches of Ag possibly exposed at the surface in this case may be less active for the activation of oxygen and be more efficiently poisoned by the adsorption of reagents and intermediates. In any event, it is remarkable that also under these conditions, the addition of the base is beneficial and helps activate the catalyst. 
The influence of water on the catalytic performance was investigated with water dilution experiments (up to $60 \mathrm{vol} \%$ of water). Under basic conditions as well as under neutral conditions the same behavior was observed: The methyl formate production decreased significantly as large water contents were present in the reaction mixture (Figure S8). The strong decrease in production of the self-coupling product was formerly explained by the formation of a germinal diol by reaction of water with the surface bonded formaldehyde [5]. If enough reactive oxygen is present such a diol could be further oxidized to the corresponding acid [40], which we did not observe. In our case reactive oxygen is limited and it is rather likely that the catalytic cycle is inhibited by the (re-)formation of an alcohol.

Moreover, different types of added bases were studied. As mentioned before, all $\mathrm{OH}^{-}$-containing bases showed the same behavior, revealing that the type of cation plays no role. Yet the employed anion, this means whether $\mathrm{CO}_{3}{ }^{2-}, \mathrm{HCO}_{3}{ }^{-}$, formate, $\mathrm{OMe}^{-}$, or $\mathrm{OH}^{-}$was used as a base, played a role (Figure S5b). The conversion of methanol to methyl formate was increased in this sequence. This trend can be explained if assuming that $\mathrm{OH}^{-}$is the key species affecting the catalytic reaction and is formed due to the reaction of the weaker bases with the water traces in the reaction mixture as a function of the $\mathrm{pK}_{\mathrm{B}}$ value of the base.

To finally clarify whether the promoting effect of the base depends on the reaction conditions, the oxygen pressure and the reaction temperature were varied under neutral and basic $(12 \mathrm{mM} \mathrm{KOH}$ in methanol) conditions (Figure 4). At 1 bar $_{2}$ the reaction did not proceed at all; this result is in line with previous studies [5] and can be explained by the very low oxygen solubility in methanol under these conditions presumably preventing the reaction to proceed [41,42]. However, at an oxygen pressure of $3 \mathrm{bar}$, the reaction takes place and the MeFm formation reached its maximum after $24 \mathrm{~h}$ in the presence and absence of the base. A further increase of the oxygen pressure did not result in a higher MeFm production and the difference between basic and neutral conditions stayed the same. (The slight decrease seen at higher oxygen pressures in both cases lies within the error bars-except for one data point-and is most likely statistically not relevant.) The variation of reaction temperature from $40{ }^{\circ} \mathrm{C}$ to $80^{\circ} \mathrm{C}$ results in an increase of the total conversion to methyl formate after $24 \mathrm{~h}$ as expected but had no apparent effect on the selectivity. Since a nearly constant offset between basic and neutral conditions is observed, it can be concluded that also the temperature (in the investigated range) does not affect the promoting influence of the base. As can be deduced from Figure 4 and Figure S9, this is in agreement with a basically temperature independent activation period under neutral conditions and an almost identical increase of the activity with the reaction temperature indicating that the rate-determining step is the same under both conditions.

In essence, our results suggest that an added base increases the yield of MeFm after a given time but not by increasing the activity as previously reported for the aerobic oxidation of d-glucose over $\mathrm{npAu}[30]$, but due to a suppression of an activation period otherwise observed for the npAu catalysts. How can this effect be explained?

As far as the catalytic mechanism of methanol oxidation on $\mathrm{Au}$ is concerned there is general agreement that it proceeds as follows: methanol reacts with adsorbed oxygen atoms originating from the activation and dissociation of molecular oxygen on Ag sites in the case of npAu to form methoxy species $\left(\mathrm{OCH}_{3}\right)$, which in turn undergo further hydrogen elimination resulting in surface-bonded formaldehyde $\left(\mathrm{O}=\mathrm{CH}_{2}\right)$. The latter species reacts further with surrounding methoxy species to yield the self-coupling product MeFm, which finally desorbs from the surface $[2,5-7,43,44]$. The loss of the hydrogen atom from the methyl group (H-elimination step) is believed to exhibit the highest activation barrier (based on UHV-studies on $\mathrm{Au}(111)$ ) and thus to represent the rate-limiting step [45]. Our experimental results suggest that this mechanism is not changed by the addition of $\mathrm{OH}^{-}$. We basically observe the same catalytic activity with and without added base, in the latter case as soon as the catalyst is active. Moreover, the same dependence on oxygen partial pressure and reaction temperature is found in both cases. The main difference, i.e., the most drastic effect of the base concerns the lack of an activation period. Under neutral conditions, it takes as long as $\sim 10 \mathrm{~h}$ before the npAu catalyst shows a decent activity while high catalytic activity is detected under basic conditions right from the beginning. 


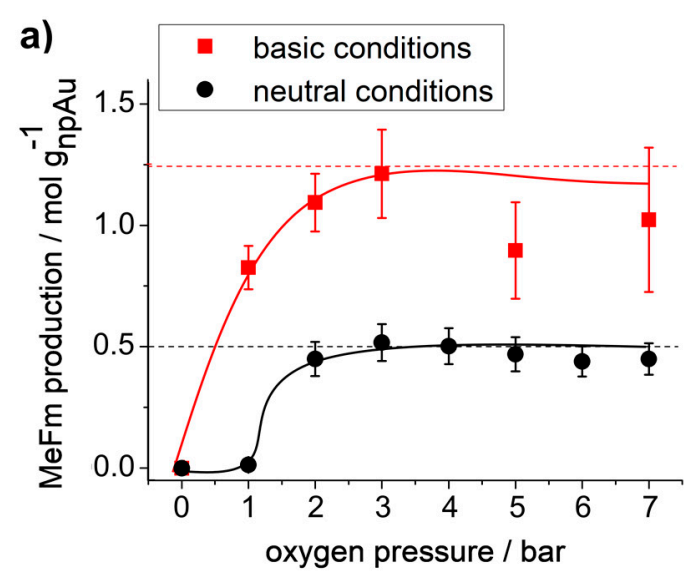

b)

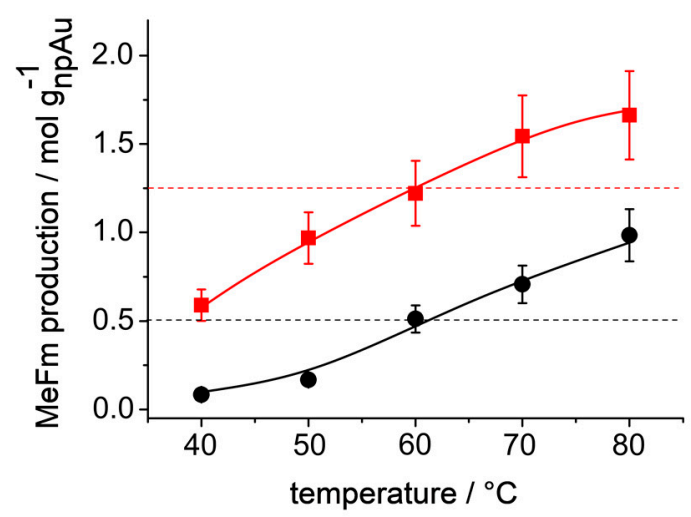

Figure 4. (a) MeFm production as a function of oxygen pressure at $60^{\circ} \mathrm{C}$ and (b) of temperature at 3 bar $\mathrm{O}_{2}$. The catalytic experiments were performed under basic conditions ( $12 \mathrm{mM} \mathrm{MOH}$ in methanol) and neutral conditions over npAu containing less than $1 \mathrm{at} \%$ Ag residues for $24 \mathrm{~h}$.

\section{Discussion}

In principle, two ways are conceivable in which $\mathrm{OH}^{-}$can reduce or prevent the activation period, i.e., can help to activate the npAu catalyst. On the one hand, it could be responsible for a fast removal of contaminants that block active surface sites and accumulated on the surface between catalyst preparation and catalytic application. The observation that we did not notice a dependence on the extend of the promoting effect of the base as a function of storage time and conditions renders this explanation as the main or only explanation, however, unlikely. More likely is the assistance of $\mathrm{OH}^{-}$ in the activation of molecular oxygen, as described already in the introduction. Due to the transient adsorption of $\mathrm{OH}^{-}$on the surface, electrons are donated to the d-band of the metallic catalyst:

$$
\mathrm{OH}^{-} \rightarrow \mathrm{OH}^{*}+\mathrm{e}^{-}
$$

In the same way, methoxide generated in the solution by abstraction of $\mathrm{H}^{+}$by $\mathrm{OH}^{-}$could act:

$$
\mathrm{CH}_{3} \mathrm{OH}+\mathrm{OH}^{-} \rightarrow \mathrm{CH}_{3} \mathrm{O}^{-}+\mathrm{H}_{2} \mathrm{O} \rightarrow \mathrm{CH}_{3} \mathrm{O}^{*}+\mathrm{e}^{-}+\mathrm{H}_{2} \mathrm{O}
$$

In this case, not only electrons are donated, but also the concentration of methoxy on the surface would be (transiently) increased. Due to the low pKs value of methanol, however, the equilibrium concentration of methoxide in the reaction mixture should be much lower, as compared to $\mathrm{OH}^{-}$so that 
this possibility should be of negligible importance. The electrons provided are then available at other sites of the surface for the reduction of molecular oxygen dissolved in the solution:

$$
\frac{1}{2} \mathrm{O}_{2}+2 \mathrm{e}^{-} \rightarrow \mathrm{O}^{2-}
$$

By forming silver oxide species on the surface (the formation of which is much more likely than the formation of (surface) Au oxides) the cycle can be closed and $\mathrm{OH}^{-}$released back into the liquid phase so that, in total, it is not consumed:

$$
2 \mathrm{Ag}+\mathrm{O}^{2-}+2 \mathrm{OH}^{*} \rightarrow \mathrm{Ag}_{2} \mathrm{O}+2 \mathrm{OH}^{-}
$$

In the following, the formed oxide species can be reduced again by participating in the oxidation of methanol resulting in metallic Ag again. Postulating a silver oxide species seems speculative on first sight but in electrocatalytic measurements of methanol oxidation under alkaline conditions XPS measurements indeed revealed, apart from metallic silver, an Ag species the binding energy of which is compatible with $\mathrm{Ag}_{2} \mathrm{O}$ [46].

Why this proposed mechanism could get the methanol oxidation directly started becomes clear in view of studies showing that npAu can be efficiently activated for the gas phase oxidation of methanol by a pre-treatment of the catalyst with ozone as mentioned above [45]. This pre-treatment was demonstrated to result not only in an oxide layer on gold (due to the harsh conditions) but also in the oxidation of all Ag present on and near the catalyst surface. In other words, the treatment led to an enrichment of silver at the surface also in agreement with UHV studies in which Ag segregation was observed in the presence of adsorbed oxygen [47]. As silver is considered to be responsible for the activation of oxygen, the combination of reaction (1) and (3) in connection with reaction (4) could similarly lead to a fast availability of $\mathrm{Ag}$ at the surface. Of course, a concomitant surface restructuring and/or subsequent generation of new oxygen species, which are specifically active for the selective oxidation of methanol, as suggested by Friend et al. in the case of ozone activation [47], cannot be excluded. Due to the direct availability of reactive oxygen on the surface as a result of the promoting effect of $\mathrm{OH}^{-}$, the oxidative removal of hydrocarbons potentially present in the beginning and poisoning the catalytic surface could be initiated as well contributing to the instantaneous onset of the catalytic reaction.

\section{Materials and Methods}

\subsection{Preparation of AuAg Alloys}

Alloy disks (5 mm diameter, $0.15 \pm 0.05 \mathrm{~mm}$ thick) with composition $\mathrm{Au}_{x} \mathrm{Ag}_{100-x}(x=25,30 \mathrm{at} \%$ $\mathrm{Au}$ ) were prepared at the Technical University Hamburg, Germany. Before dealloying, they were annealed at $850{ }^{\circ} \mathrm{C}$ for 3 days to achieve a homogeneous distribution of $\mathrm{Ag}$ and $\mathrm{Au}$ and to release mechanical stress in the material. Nitric acid $\left(\mathrm{HNO}_{3}, \geq 65 \%\right.$, Sigma-Aldrich, Munich, Germany) was used to prepare the dealloying solutions.

\subsection{Preparation of Nanoporous Gold (npAu)}

The npAu samples were obtained in two different ways, i.e., by free corrosion (FC) and galvanodynamically controlled dealloying (GCD). More details regarding both npAu synthesis routes are reported in previous publications $[5,13,36]$.

FC: The AuAg alloy disks were submerged in concentrated $\mathrm{HNO}_{3}$ for $24 \mathrm{~h}$.

GCD: A three-electrode-system was used with the AuAg alloy disk mounted on a gold wire as working electrode (WE) and platinum wires as counter (Aux) and quasi reference electrode (QRE). The dealloying was carried out with a potentiostat (Bio-Logic SP-200, Seyssinet-Pariset, France) and performed in $5 \mathrm{M} \mathrm{HNO}_{3}$ at room temperature applying the following program: Current of $5 \mathrm{~mA} / \mathrm{cm}^{2}$ 
for $1.5 \mathrm{~h}$, then $1 \mathrm{~mA} / \mathrm{cm}^{2}$ for $4 \mathrm{~h}$, and finally $0.2 \mathrm{~mA} / \mathrm{cm}^{2}$ until a specified fraction of the initial silver content was dissolved by monitoring the converted charge.

Afterwards, the npAu samples were washed at least three times in both cases with deionized water and dried in air over night.

\subsection{Characterization of $n p A u$}

The elemental composition of npAu after preparation was checked by Atomic Absorption Spectroscopy (AAS 5 FL, Jena Analytik, Jena, Germany). To this end, samples were dissolved in aqua regia at about $60^{\circ} \mathrm{C}$ overnight prior to the AAS measurements.

The specific surface areas of npAu samples containing less than 1 at $\%$ Ag was determined by cyclic voltammogram measurements, as previously reported [5]. For samples with higher residual $\mathrm{Ag}$ contents, the specific surface area could not be determined by this method due to formation of insoluble $\mathrm{Ag}_{2} \mathrm{SO}_{4}$ during the process. Briefly, the scans were performed from $-0.4 \mathrm{~V}$ to +2 in $0.5 \mathrm{M}$ sulfuric acid $\left(\mathrm{H}_{2} \mathrm{SO}_{4}, 95 \%\right.$, VWR Chemicals, Hanover, Germany) with scan rates of 1-100 mV/s ${ }^{2}$ using a potentiostat (Bio-Logic SP-200, Seyssinet-Pariset, France). NpAu was mounted on a gold wire as WE, a Pt wire was used as $\mathrm{Aux}$ and $\mathrm{Ag} / \mathrm{AgCl}$ as a reference electrode (Equation S1).

Structural characterization of npAu was carried out by scanning electron microscopy (SEM, Zeiss Supra 40, Oberkochen, Germany) before and after catalysis with the following parameters: $15.00 \mathrm{kV}$ acceleration voltage, $300 \mathrm{pA}$ probe current and $9.8 \mathrm{~mm}$ working distance. The mean ligament size of each sample was determined by measuring the diameter of 200 ligaments sizes in cross section close to the outer surface as well as at the center to confirm the homogeneity of the porous structure throughout the whole monolith, as already reported in Ref. [36].

Also structural characterization of a representative npAu sample after catalysis was performed by transmission electron microscopy (TEM) in the same way as already previously described [5]. For these measurements, thin electron transparent lamellas were cut with Focused Ion Beam (FIB) using a FEI Nova 200 FIB. TEM measurements were performed in the bright field mode using parallel illumination in a FEI Titan 80/300 (S)TEM microscope equipped with a Cs-corrector for the objective lens. The density of low coordinated surface atoms was determined by measuring the separations between surface steps in two-dimensional projections in HRTEM images, as already described in previous studies [5]. Different crystallographic orientations $\langle 112\rangle,\langle 110\rangle$, and $\langle 001\rangle$ were analyzed and the overall average density of low coordinated surface atoms was obtained by weighting the results for the different directions with the corresponding reciprocal surface energies [5].

\subsection{Alcohol Oxidation Experiments}

Liquid phase methanol (MeOH, VWR Chemicals, $99.8 \%$, Hanover, Germany) oxidation experiments were performed in a batch reactor (AmAr Equiptments PVT. LTD., Mumbai, India; reaction volume of $60-450 \mathrm{~mL}$ ). The reactor was filled with $60 \mathrm{~mL}$ of the alcohol and the base (10-500 mg) was added. After sealing the reactor, it was purged first with nitrogen $\left(\mathrm{N}_{2}\right.$, Linde 5.0, Hamburg, Germany) and then with oxygen $\left(\mathrm{O}_{2}\right.$, Linde 5.0, Hamburg, Germany) at least three times. Afterwards, the reactor was pressured with the desired oxygen pressure (1-7 bar $\left.\mathrm{O}_{2}\right)$ and heated to the desired temperature $\left(40-80^{\circ} \mathrm{C}\right)$ for at least $24 \mathrm{~h}$ while stirring the reaction mixture at $4 \mathrm{rps}$ [5]. It is important to note in the following that methanol was used in large excess so that a pseudo zero order kinetics with respect to methanol can be assumed. On the contrary, the base was applied only in catalytic amounts meaning that the conversions of methanol reported in the following are significantly larger than the amount of base added.

As base different hydroxide bases (potassium hydroxide, $\mathrm{KOH}, \geq 85 \%$ containing $<2.3 \%$ non-relevant traces for catalysis, and 10-15\% water as impurities, Sigma-Aldrich, Munich, Germany; sodium hydroxide, $\mathrm{NaOH},>99 \%$, Riedel-De Haën, Seelze, Germany; lithium hydroxide, $\mathrm{LiOH}$, Fluorochem, Derbyshire, UK, reagent grade) were used. (Note that all bases are hygroscopic; no attempt was made to use water-free reagents since water is a reaction product anyways.) While 
small amounts of water had no influence on the catalytic results, the excess water had an effect as described in Section 3.) In addition, other bases not containing $\mathrm{OH}^{-}$(potassium methanolate, $\mathrm{KOMe}$, $90 \%+$, Alfa Aesar, Heysham, UK; potassium carbonate, $\mathrm{K}_{2} \mathrm{CO}_{3},>99.9 \%$, Merck, Darmstadt, Germany; potassium hydrogen carbonate, $\mathrm{KHCO}_{3},>99.5 \%$, Riedel-De Haën, Seelze, Germany; potassium formate, KFm, $>99 \%$ Sigma-Aldrich, Munich, Germany) were added to analyze the effect of the base anion.

\subsection{Analysis of Oxidation Products}

The liquid phase was analyzed typically after $24 \mathrm{~h}$ in order to identify the reaction products and their concentration with a gas chromatograph coupled with a mass spectrometer (GC/MS, Agilent 5975C, Hamburg, Germany; column INNOPEG 1000, $50 \mathrm{~m} \times 250 \mu \mathrm{m} \times 0.1 \mu \mathrm{m}$, inert XL MSD, MS equipped with Triple-Axis Detector), as already described in a previous publication [5]. The amount of $\mathrm{CO}_{2}$ in the case phase possibly formed by total oxidation could not be detected due to experimental limitations.

\section{Conclusions}

The aerobic oxidation of methanol over nanoporous gold catalyst is affected by the addition of a base. In contrast to supported Au nanoparticles for which a beneficial effect of basic conditions was observed [48], and npAu is an unsupported catalyst so that our study allows drawing conclusions regarding the interaction of $\mathrm{OH}^{-}$exclusively with the metallic surface. We find that the activation period of the catalyst, which takes up to about $10 \mathrm{~h}$ under neutral conditions is circumvented, i.e., effectively suppressed. The rate of formation of methyl formate-in case of neutral conditions observed after the activation period-is in both cases comparable. This and the fact that neither the selectivity is changed upon addition of the base nor a different dependence of the catalyst activity on the oxygen partial pressure and the reaction temperature is found implies that the reaction mechanism established in the literature for the partial oxidation of methanol on $\mathrm{Au}$ is the same. Rather, we propose that the adsorption of $\mathrm{OH}^{-}$at the surface enables a distinctly faster (possibly instantaneous) activation of molecular oxygen, by donating electrons and that this concomitantly leads to segregation of $\mathrm{Ag}$ to the surface. A similar effect was formerly reported for the pretreatment of npAu with ozone [47]. Additionally, in this case, an efficient activation of npAu occurred and ascribed to the migration of surface near Ag to the surface driven by the formation of oxidic Ag species. Notably, the formation of an $\mathrm{Ag}_{2} \mathrm{O}$ species was observed under alkaline electrocatalytic conditions as well [49]. In essence, the abundance of $\mathrm{Ag}$ responsible for the activation of oxygen at the surface can be efficiently increased so that active surface oxygen becomes directly (or very fast) available for the oxidation of adsorbed methanol when the catalyst comes into contact with the reaction mixture.

In future work, routes to modify npAu or its surface chemistry, respectively, shall be explored to broaden the scope of applicability of npAu as a catalyst for oxidation reactions. In particular, we plan to employ underpotential deposition of Ag to subsequently add sub-monolayer amounts of Ag to the surface of npAu-a procedure already successfully applied for Au nanoparticles [50]. In this way, the Ag surface concentration can be more precisely controlled than by varying the Ag bulk content of the samples, which only indirectly determines the Ag surface concentration by surface segregation. Not only this should be another means to achieve immediate activity for $\mathrm{O}_{2}$ activation (without $\mathrm{Ag}$ segregation from the bulk to the surface); this approach should also allow tuning the oxidation power of the npAu catalyst, i.e., its ability to catalyze a broader range of oxidation reactions ranging from partial to total oxidation.

Supplementary Materials: The following are available online at http://www.mdpi.com/2073-4344/9/5/416/s1, Figure S1: Representative SEM images and corresponding histograms, Figure S2: Representative SEM images and corresponding histograms, Figure S3: Representative SEM images and corresponding histograms, Figure S4: TEM images from a lamella cut from the center of the npAu disk, Figure S5: MeFm formation over npAu samples under different catalytic conditions, Figure S6: MeFm formation as a function of time, Figure S7: MeFm production over $\mathrm{npAu}$ with various residual Ag content, Figure S8: MeFm production as a function of MeOH content dilution with water, Figure S9: MeFm production as a function of time at different temperatures, Table S1: MeFm production and corresponding turnover frequencies. 
Author Contributions: Conceptualization, A.W. and A.L.; methodology, A.L. and C.M.; formal analysis, A.L.; investigation, A.L.; resources, A.W., M.B. and A.R.; writing-original draft preparation, A.L.; writing-review and editing, A.W. and M.B.; visualization, A.L.; supervision, A.W.; funding acquisition, A.W., A.R., M.B.

Funding: This work was supported within the Interregio Research Unit FOR2213 by the German Science Foundation (WI 4497/1, RO 2057/12-2 and BA 1710/29-1).

Acknowledgments: A.L. gratefully acknowledges help of Petra Witte (Department of Historic Geology and Paleontology, Universität Bremen, Germany) with the SEM measurements and of Lisa Fitzek (Institute of Materials Physics and Technology, Technische Unversität Hamburg, Germany) with the AuAg alloy preparation. We kindly acknowledge the University Bremen for central payment.

Conflicts of Interest: The authors declare no conflict of interest.

\section{References}

1. Wittstock, A.; Biener, J.; Erlebacher, J.; Bäumer, M. Nanoporous gold: From an Ancient Technology to a High-Tech Material; RSC Publishing: London, UK, 2012.

2. Personick, M.L.; Madix, R.J.; Friend, C.M. Selective Oxygen-Assisted Reactions of Alcohols and Amines Catalyzed by Metallic Gold: Paradigms for the Design of Catalytic Processes. ACS Catal. 2017, 7, $965-985$. [CrossRef]

3. Sharma, A.S.; Kaur, H.; Shah, D. Selective oxidation of alcohols by supported gold nanoparticles: Recent advances. RSC Adv. 2016, 6, 28688-28727. [CrossRef]

4. Nielsen, I.S.; Taarning, E.; Egeblad, K.; Madsen, R.; Christensen, C.H. Direct aerobic oxidation of primary alcohols to methyl esters catalyzed by a heterogeneous gold catalyst. Catal. Lett. 2007, 116, 35-40. [CrossRef]

5. Lackmann, A.; Mahr, C.; Schowalter, M.; Fitzek, L.; Weissmüller, J.; Rosenauer, A.; Wittstock, A. A comparative study of alcohol oxidation over nanoporous gold in gas and liquid phase. J. Catal. 2017, 353, 99-106. [CrossRef]

6. Wittstock, A.; Zielasek, V.; Biener, J.; Friend, C.M.; Bäumer, M. Nanoporous Gold Catalysts for Selective Gas-Phase Oxidative Coupling of Methanol at Low Temperature. Science 2010, 327, 319-322. [CrossRef]

7. Kosuda, K.M.; Wittstock, A.; Friend, C.M.; Bäumer, M. Oxygen-Mediated Coupling of Alcohols over Nanoporous Gold Catalysts at Ambient Pressures. Angew. Chem. Int. Ed. 2012, 51, 1698-1701. [CrossRef]

8. Jürgens, B.; Kübel, C.; Schulz, C.; Nowitzki, T.; Zielasek, V.; Biener, J.; Biener, M.M.; Hamza, A.V.; Bäumer, M. New gold and silver-gold catalysts in the shape of sponges and sieves. Gold Bull. 2007, 40, 142-149. [CrossRef]

9. Zielasek, V.; Jürgens, B.; Schulz, C.; Biener, J.; Biener, M.M.; Hamza, A.V.; Bäumer, M.; Bäumer, M. Gold Catalysts: Nanoporous Gold Foams. Angew. Chem. Int. Ed. 2006, 45, 8241-8244. [CrossRef]

10. Xu, C.; Su, J.; Xu, X.; Liu, P.; Zhao, H.; Tian, F.; Ding, Y. Low Temperature CO Oxidation over Unsupported Nanoporous Gold. J. Am. Chem. Soc. 2007, 129, 42-43. [CrossRef] [PubMed]

11. Wittstock, A.; Bäumer, M. Catalysis by Unsupported Skeletal Gold Catalysts. Accounts Chem. Res. 2014, 47, 731-739. [CrossRef] [PubMed]

12. Fujita, T.; Guan, P.; McKenna, K.; Lang, X.; Hirata, A.; Zhang, L.; Tokunaga, T.; Arai, S.; Yamamoto, Y.; Tanaka, N.; et al. Atomic origins of the high catalytic activity of nanoporous gold. Nat. Mater. 2012, 11, 775-780. [CrossRef] [PubMed]

13. Mahr, C.; Kundu, P.; Lackmann, A.; Zanaga, D.; Thiel, K.; Schowalter, M.; Schwan, M.; Bals, S.; Wittstock, A.; Rosenauer, A. Quantitative determination of residual silver distribution in nanoporous gold and its influence on structure and catalytic performance. J. Catal. 2017, 352, 52-58. [CrossRef]

14. López, N.; Nørskov, J.K. Catalytic CO Oxidation by a Gold Nanoparticle: A Density Functional Study. J. Am. Chem. Soc. 2002, 124, 11262-11263. [CrossRef]

15. Wang, L.C.; Zhong, Y.; Widmann, D.; Weissmüller, J.; Behm, R.J. On the Role of Residual Ag in Nanoporous Au Catalysts for CO Oxidation: A Combined Microreactor and TAP Reactor Study. Chemcatchem 2012, 4, 251-259. [CrossRef]

16. Wang, L.-C.; Zhong, Y.; Jin, H.; Widmann, D.; Weissmüller, J.; Behm, R.J.; Ziemann, P.; Schimmel, T. Catalytic activity of nanostructured Au: Scale effects versus bimetallic/bifunctional effects in low-temperature CO oxidation on nanoporous Au. Beilstein J. Nanotechnol. 2013, 4, 111-128. [CrossRef]

17. Déronzier, T.; Morfin, F.; Lomello, M.; Rousset, J.-L. Catalysis on nanoporous gold-silver systems: Synergistic effects toward oxidation reactions and influence of the surface composition. J. Catal. 2014, 311, 221-229. [CrossRef] 
18. Moskaleva, L.V.; Röhe, S.; Zielasek, V.; Neyman, K.M.; Wittstock, A.; Klüner, T.; Bäumer, M. Silver residues as a possible key to a remarkable oxidative catalytic activity of nanoporous gold. Phys. Chem. Chem. Phys. 2011, 13, 4529-4539. [CrossRef]

19. Moskaleva, L.V.; Weiss, T.; Kluener, T.; Bäumer, M.; Klüner, T. Chemisorbed Oxygen on the Au(321) Surface Alloyed with Silver: A First-Principles Investigation. J. Phys. Chem. C 2015, 119, 9215-9226. [CrossRef]

20. Fajin, J.L.C.; Gomes, J.R.B.; Fajín, J.L.C.; Cordeiro, M.N.D.S. On the theoretical understanding of the unexpected $\mathrm{O}_{2}$ activation by nanoporous gold. Chem. Commun. 2011, 47, 8403-8405. [CrossRef]

21. Montemore, M.M.; Madix, R.J.; Kaxiras, E. How Does Nanoporous Gold Dissociate Molecular Oxygen? J. Phys. Chem. C 2016, 120, 16636-16640. [CrossRef]

22. Hoppe, S.; Li, Y.; Moskaleva, L.V.; Müller, S. How silver segregation stabilizes 1D surface gold oxide: A cluster expansion study combined with ab initio MD simulations. Phys. Chem. Chem. Phys. 2017, 19, 14845-14853. [CrossRef] [PubMed]

23. Wittstock, A.; Neumann, B.; Schaefer, A.; Dumbuya, K.; Kübel, C.; Biener, M.M.; Zielasek, V.; Steinrück, H.-P.; Gottfried, J.M.; Biener, J.; et al. Nanoporous Au: An Unsupported Pure Gold Catalyst? J. Phys. Chem. C 2009, 113, 5593-5600. [CrossRef]

24. Zhang, Y.; Cui, X.J.; Shi, F.; Deng, Y.Q. Nano-Gold Catalysis in Fine Chemical Synthesis. Chem. Rev. 2012, 112, 2467-2505. [CrossRef]

25. Hashmi, A.S.K.; Hutchings, G.J. Gold catalysis. Angew. Chem. Int. Ed. 2006, 45, 7896-7936. [CrossRef]

26. Oliveira, R.L.; Kiyohara, P.K.; Rossi, L.M. Clean preparation of methyl esters in one-step oxidative esterification of primary alcohols catalyzed by supported gold nanoparticles. Green Chem. 2009, 11, 1366-1370. [CrossRef]

27. Klitgaard, S.K.; Riva, A.T.D.; Helveg, S.; Werchmeister, R.M.; Christensen, C.H. Aerobic Oxidation of Alcohols over Gold Catalysts: Role of Acid and Base. Catal. Lett. 2008, 126, 213-217. [CrossRef]

28. Zheng, N.; Stucky, G.D. Promoting gold nanocatalysts in solvent-free selective aerobic oxidation of alcohols. Chem. Commun. 2007, 37, 3862-3864. [CrossRef]

29. Yang, J.; Guan, Y.; Verhoeven, T.; Van Santen, R.; Li, C.; Hensen, E.J.M. ChemInform Abstract: Basic Metal Carbonate Supported Gold Nanoparticles: Enhanced Performance in Aerobic Alcohol Oxidation. ChemInform 2009, 40, 322-325. [CrossRef]

30. Yin, H.; Zhou, C.; Xu, C.; Liu, P.; Xu, X.; Ding, Y. Aerobic Oxidation of d-Glucose on Support-Free Nanoporous Gold. J. Phys. Chem. C 2008, 112, 9673-9678. [CrossRef]

31. Shang, C.; Liu, Z.-P. Origin and Activity of Gold Nanoparticles as Aerobic Oxidation Catalysts in Aqueous Solution. J. Am. Chem. Soc. 2011, 133, 9938-9947. [CrossRef]

32. Zope, B.N.; Hibbitts, D.D.; Neurock, M.; Davis, R.J. Reactivity of the Gold/Water Interface during Selective Oxidation Catalysis. Science 2010, 330, 74-78. [CrossRef] [PubMed]

33. Xu, F.; Fampiou, I.; O'Connor, C.R.; Karakalos, S.; Hiebel, F.; Kaxiras, E.; Madix, R.J.; Friend, C.M. Water facilitates oxygen migration on gold surfaces. Phys. Chem. Chem. Phys. 2018, 20, 2196-2204. [CrossRef]

34. Quiller, R.G.; Baker, T.A.; Deng, X.; Colling, M.E.; Min, B.K.; Friend, C.M. Transient hydroxyl formation from water on oxygen-covered Au(111). J. Chem. Phys. 2008, 129, 064702. [CrossRef]

35. Xu, B.; Haubrich, J.; Baker, T.A.; Kaxiras, E.; Friend, C.M. Theoretical Study of O-Assisted Selective Coupling of Methanol on Au(111). J. Phys. Chem. C 2011, 115, 3703-3708. [CrossRef]

36. Lackmann, A.; Wittstock, G.; Bäumer, M.; Wittstock, A. Independent control over residual silver content of nanoporous gold by galvanodynamically controlled dealloying. Nanoscale 2018, 10, 17166-17173. [CrossRef]

37. Personick, M.L.; Zugic, B.; Biener, M.M.; Biener, J.; Madix, R.J.; Friend, C.M. Ozone-Activated Nanoporous Gold: A Stable and Storable Material for Catalytic Oxidation. ACS Catal. 2015, 5, 4237-4241. [CrossRef]

38. Langille, M.R.; Personick, M.L.; Mirkin, C.A. Plasmon-Mediated Syntheses of Metallic Nanostructures. Angew. Chem. Int. Ed. 2013, 52, 13910-13940. [CrossRef]

39. Menumerov, E.; Hughes, R.A.; Golze, S.D.; Neal, R.D.; DeMille, T.B.; Campanaro, J.C.; Kotesky, K.C.; Rouvimov, S.; Neretina, S. Identifying the True Catalyst in the Reduction of 4-Nitrophenol: A Case Study Showing the Effect of Leaching and Oxidative Etching Using Ag Catalysts. ACS Catal. 2018, 8, 8879-8888. [CrossRef]

40. Fristrup, P.; Johansen, L.B.; Christensen, C.H. Mechanistic investigation of the gold-catalyzed aerobic oxidation of alcohols. Catal. Lett. 2008, 120, 184-190. [CrossRef]

41. Fischer, K.; Wilken, M. Experimental determination of oxygen and nitrogen solubility in organic solvents up to $10 \mathrm{MPa}$ at temperatures between $298 \mathrm{~K}$ and $398 \mathrm{~K}$. J. Chem. Thermodyn. 2001, 33, 1285-1308. [CrossRef] 
42. Battino, R.; Rettich, T.R.; Tominaga, T. The Solubility of Oxygen and Ozone in Liquids. J. Phys. Chem. Ref. Data 1983, 12, 163. [CrossRef]

43. Stowers, K.; Madix, R.; Friend, C. From model studies on Au(111) to working conditions with unsupported nanoporous gold catalysts: Oxygen-assisted coupling reactions. J. Catal. 2013, 308, 131-141. [CrossRef]

44. Wang, L.-C.; Personick, M.L.; Karakalos, S.; Fushimi, R.; Friend, C.M.; Madix, R.J. Active sites for methanol partial oxidation on nanoporous gold catalysts. J. Catal. 2016, 344, 778-783. [CrossRef]

45. Xu, B.J.; Liu, X.Y.; Haubrich, J.; Friend, C.M. Vapour-phase gold-surface-mediated coupling of aldehydes with methanol. Nat. Chem. 2010, 2, 61-65. [CrossRef] [PubMed]

46. Graf, M.; Haensch, M.; Carstens, J.; Wittstock, G.; Weissmüller, J. Electrocatalytic methanol oxidation with nanoporous gold: Microstructure and selectivity. Nanoscale 2017, 9, 17839-17848. [CrossRef]

47. Zugic, B.; Wang, L.C.; Heine, C.; Zakharov, D.N.; Lechner, B.A.J.; Stach, E.A.; Biener, J.; Salmeron, M.; Madix, R.J.; Friend, C.M. Dynamic restructuring drives catalytic activity on nanoporous gold-silver alloy catalysts. Nat. Mater. 2017, 16, 558-564. [CrossRef] [PubMed]

48. Ide, M.S.; Davis, R.J. The Important Role of Hydroxyl on Oxidation Catalysis by Gold Nanoparticles. Accounts Chem. Res. 2014, 47, 825-833. [CrossRef]

49. Graf, M.; Roschning, B.; Weissmüller, J. Nanoporous Gold by Alloy Corrosion: Method-Structure-Property Relationships. J. Electrochem. Soc. 2017, 164, C194-C200. [CrossRef]

50. Personick, M.L.; Langille, M.R.; Zhang, J.; Mirkin, C.A. Shape Control of Gold Nanoparticles by Silver Underpotential Deposition. Nano Lett. 2011, 11, 3394-3398. [CrossRef]

(C) 2019 by the authors. Licensee MDPI, Basel, Switzerland. This article is an open access article distributed under the terms and conditions of the Creative Commons Attribution (CC BY) license (http://creativecommons.org/licenses/by/4.0/). 